\title{
Intertrial reinforcement and aftereffects at 24-hour intervals'
}

\author{
E. J. Capaldi and James E. Spivey \\ UNIVERSITY OF TEXAS
}

\begin{abstract}
Two experiments employing rats in the runway and intertrial reinforcement tested and confirmed the hypothesis that a given aftereffect remains functional until replaced by another aftereffect.
\end{abstract}

\section{Problem}

The generally accepted view is that aftereffects persist only in terms of minutes (e. g., Lawrence \& Festinger, 1962; Weinstock, 1954). Capaldi et al. (1963) assumed, on the contrary, that a given aftereffect remains functional until such time as it is replaced by another aftereffect. The present investigations employed intertrial reinforcement, or ITR, (Capaldi et al., 1963; Capaldi \& Spivey, 1963) to determine if aftereffects remain functional for $24 \mathrm{hr}$.

The runway procedure may be divided into four phases: (1) runway traversal, (2) goal box confinement, (3) goal box removal and intertrial interval, and (4) succeeding trial or home-cage return. Placing $S$ in a baited goal box, or ITR, occurs between 3 and 4 . Its object when given following nonreinforcement is to replace the aftereffect of nonreinforcement with that of reinforcement, which from an aftereffects viewpoint should reduce the partial reinforcement effect.

\section{Method}

Experiment I had 30 and Experiment II, 60 naive male Holtzman rats about 90 days old at the experiment's beginning. Handling and adjustment to the approximately $23 \mathrm{hr}$. of food deprivation (mash was fed in the home cage and goal box) were identical to the procedures employed by Capaldi \& Spivey (1963) except that 20 (Exp. I) and 18 (Exp. II), rather than 10, days of such training were employed and $\mathrm{S}$ was given about five reinforced placements in a neutral gray goal box. The 4-in wide $x \quad 7 \quad 1 / 2-f t$ long runway and L-shaped goal boxes were identical to those employed by Capaldi \& Spivey (1963)

There were three partial reinforcement groups (PB, PW, and PR) in both experiments, $10 \mathrm{Ss}$ (Exp. I) and 15 Ss (Exp. II) per group, Experiment II also including a $100 \%$ group (C). All trials were separated by $24 \mathrm{hr}$., there being 31 acquisition and 15 extinction trials (Exp. I) or 19 and 24 such trials (Exp. II). The S entered a black goal box from the alley and was confined $15 \mathrm{sec}$. on reinforced trials and $15 \mathrm{sec}$. (Exp. I) or $10 \mathrm{sec}$. (Exp. II) on all nonreinforced trials. All groups received ITR in the black goal box except Group PW (white goal box). On days when ITR was not given, $\mathrm{S}$ was removed from the goal box to a neutral waiting box for $30 \mathrm{sec}$. The $\mathrm{S}$ was then returned to the home cage and fed
$10 \mathrm{~min}$. later for $1 \mathrm{hr}$. The procedure was identical on ITR days except that $S$ was returned from the waiting box to the baited goal box for $15 \mathrm{sec}$, returned to the waiting box again for $30 \mathrm{sec}$, and then to the home cage. Groups received 6 ITR's (Exp. I) or 4 (Exp. II), Groups $\mathrm{PB}$ and $\mathrm{PW}$ receiving ITR following all nonreinforced trials preceding reinforced ones, Groups $\mathrm{PR}$ and $\mathrm{C}$, following reinforced trials. Nonreinforced trials occurred on Days 6, 8, 9, 12, 13, 16, 17, 18, 21, 22, 25, and 26 (Exp. I) or Days 5, 7, 8, 11, 12, 15, 16, and 17 (Exp. II). Group PR received ITR on Days 7, 10, 15, 19, 24, and 27 (Exp. I) and Groups PR and C, on Days 6, 9, 14, and 18 (Exp. II). The $\mathrm{S}$ was placed on the forward portion of the runway and if it did not break the photobeam (4 $1 / 2$ in from the distal end of alley) within 60 sec., it was guided to the goal box in acquisition and removed from the alley in extinction, a time score of $60 \mathrm{sec}$. being assigned.

\section{Results}

Figure 1 and Fig. 2 show the mean of the log times in Experiment I and Experiment II, respectively, on the last block of acquisition trials and on each block of extinction trials. In both experiments, among partial groups, Group PR was most with Group PB being least resistant to extinction. In Experiment II Group PB was on the whole more resistant to extinction than Group C. Terminal acquisition differences were not significant in

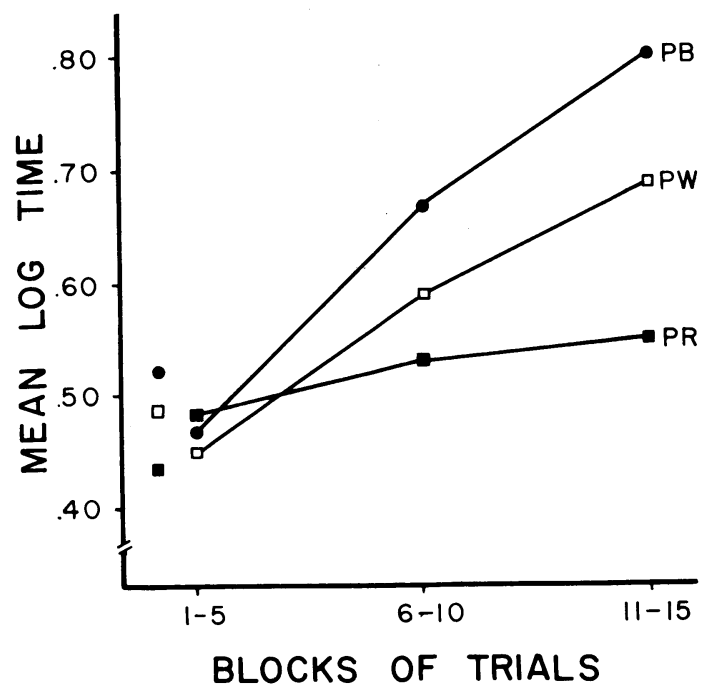

Fig. 1. Performance of each of the groups on the last five-trial block of acquisition trials (left) and on each of the five-trial blocks of extinction trials. 


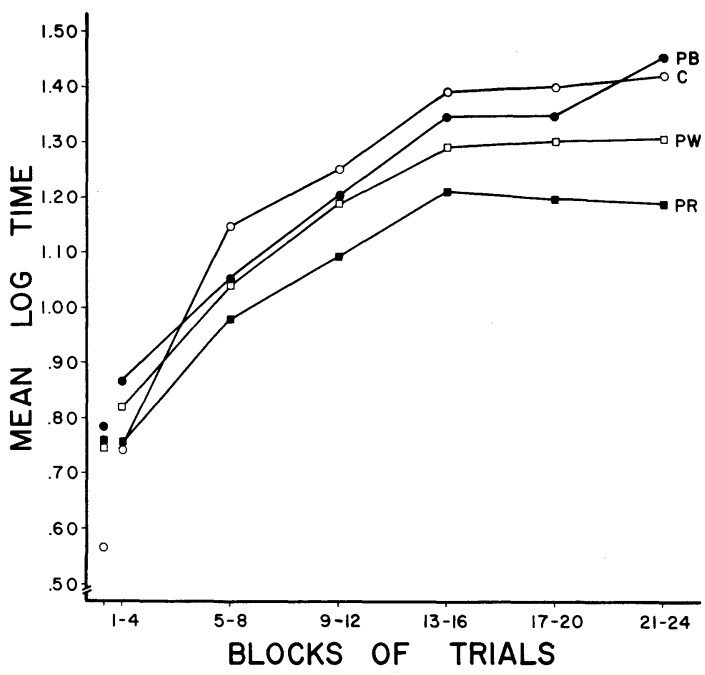

Fig. 2. Performance of each of the groups on the last four-trial block of acquisition trials (left) and on each of the four-trial blocks of extinction trials.

Experiment I ( $\mathrm{F}=1.09$; df $2 / 27)$ and approached significance in Experiment II $(F=2.43$; df $3 / 56 ; \mathrm{P}<.10)$ due to the relatively fast times of Group $C$. The groups $\mathrm{x}$ trials interaction was significant beyond the .05 level in Experiment $\mathrm{I}(\mathrm{F}=3.10 ; \mathrm{df} 4 / 45)$ and at about the .07 level in Experiment II ( $\mathrm{F}=1.65$; df $15 / 280)$, indicating that in both experiments the groups extinguished at different rates. Differences on the last block of extinction trials were significant beyond the .05 level in Experiment I ( $F=3.47$; df $2 / 27)$ and at about the .06 level in Experiment II $(F=2.75 ;$ df $3 / 56)$. The mean number of trials required to run as slow as $50 \mathrm{sec}$. in Experiment II (most Ss did not run as slow as the maximum of 60 sec.) was $\mathrm{C}, 12.33$; $\mathrm{PB}, 15.53$; PW, 18.40; and $\mathrm{PR}, 19.53(\mathrm{~F}=2.99$; df $3 / 56 ; \mathrm{P}<.05)$.

\section{Discussion}

The present spaced-trial results are consistent with those of massed-trial ITR studies (Capaldi et al., 1963; Capaldi \& Spivey, 1963) and suggest that the partial reinforcement effect under 24-hr. intervals (e. g., Weinstock, 1954) is due to aftereffects remaining functional for $24 \mathrm{hr}$. This conclusion assumes (Capaldi \& Spivey, 1963) that ITR replaced the aftereffect of nonreinforcement with that of reinforcement most extensively in Group PB, less extensively in Group PW, and least extensively or not at all in Group PR, since ITR occurred following reinforced trials. Experiment II, which replicated and extended Experiment I, demonstrated that the partial reinforcement effect (Group C vs. Group PR) can occur following a very small number of spaced trials, a result previously demonstrated with massed trials (Capaldi \& Hart, 1962).

\section{References}

CAPALDI, E. J., \& HART, D. Influence of a small number of partial reinforcement training trials on resistance to extinction. J. exp. Psychol., 1962, 64, 166-171.

CAPALDI, E. J., HART, D., \& STANLEY, L. R. Effect of intertrial reinforcement on the aftereffect of nonreinforcement and resistance to extinction. J.exp. Psychol., 1963, 65, 70-74.

CAPALDI, E. J., \& SPIVEY, J. E. Effect of goal-box similarity on the aftereffect of nonreinforcement and resistance to extinction. J.exp. Psychol., 1963, 66, 461-465.

LAWRENCE, D. H., \& FESTINGER, L. Deterrents and reinforcement. Stanford: Stanford Univer. Press, 1962. Pp. 19, 20.

WEINSTOCK, S. Resistance to extinction of a running response following partial reinforcement under widely spaced trials. J.comp. physiol. Psychol., 1954, 47, 318-322.

\section{Note}

1. This research was supported in part by National Institute of Child Health and Human Development Research Grant HD 00940-02 to the first author. 